\title{
Anti-Nuclear antibodies: Current concepts and future direction for diagnosing connective tissue disease
}

\author{
Gautam K \\ ${ }^{l}$ Department of Pathology, Samyak Diagnostic Pvt. Ltd., Lalitpur, Nepal
}

\section{Keywords:}

Autoantibodies; Indirect immunofluorescence; Antinuclear antibodies;

Systemic lupus erythematosus;

\begin{abstract}
Identification of antinuclear antibodies has been used for the diagnosis of connective tissue diseases for more than fifty years. Indirect immunofluorescence on human epithelial (HEp-2) cells is considered the gold standard screening method for the detection of antinuclear autoantibodies. As the demand of ANA testing increased, the need for automation and standardization has also come forth. A high level of false positive and false negative cases is seen in various populations making it difficult to take clinical decisions. Newer technologies were introduced for the antibody detection to ensure high sensitivity and specificity. This article intends to provide an overview of the concepts on ANA testing, the different diagnostic methods available, the various patterns and clinical utility, the clinical guidelines to be followed, the drawbacks and what lies ahead in the future of ANA testing.
\end{abstract}

\section{INTRODUCTION}

Autoantibodies are the hallmark of autoimmunity, of which anti-nuclear antibody (ANA) have taken the centre stage for the past 60 years. The term ANA is now outdated and even confusing as this historical label has come to encompass antibodies directed at various cellular compartments including nuclear constituents, components of the nuclear envelope, mitotic spindle apparatus, cytosol, cytoplasmic organelles and cell membranes. Detection of anti-cellular antibodies of the ANA family is pivotal to the diagnosis of many autoimmune disease. ${ }^{1,2}$ ANA are a specific class of autoantibodies that have the capability of binding and

\footnotetext{
Correspondence:

Dr. Keyoor Gautam, MD

Consultant Pathologist

Samyak Diagnostic Pvt. Ltd, Lalitpur, Nepal

Email:drkeyoor@samyakdiagnostic.com
}

destroying certain structures within the nucles of the cells. ${ }^{3}$ Although lower amounts of these antibodies can be seen in the normal population as well, a spurt in titers is seen in patients with connective tissue diseases (CTD). Their detection with high sensitivity and specificity is therefore of utmost importance. Various detection methods are in use and there is continuous pouring of newer technologies to facilitate the diagnosis and therapeutic monitoring in CTD patients. ${ }^{4}$ In this article we on the various diagnosing methods for ANA, interpretative patterns, guidelines for clinical use, the drawbacks and the future direction for assessing ANA.

\section{HISTORY}

In 1941, Klemperer, Pollack and Baehr first described systemic lupus erythromatosis (SLE) as one of the CTD. ${ }^{5}$ 
Table 1: Clinical utility of ANA testing in different diseases

\begin{tabular}{lllll}
\hline Diagnosis & Clinical utility & $\begin{array}{c}\text { ANA } \\
\text { prevalence } \\
(\%)\end{array}$ & $\begin{array}{l}\text { Monitoring/ } \\
\text { prognosis }\end{array}$ & Comments \\
\hline SLE & Very useful & $90-95$ & Not useful & ANA IIF superior to ANA solid phase assays \\
\hline SSc & Very useful & $85-95$ & Not useful & ANA IIF superior to ANA solid phase assays \\
\hline SjS & Useful & $50-60$ & Not useful & $\begin{array}{l}\text { ANA solid phase assays superior to ANA IFF; SS-A reactivity can be } \\
\text { missed by ANA HEp-2 }\end{array}$ \\
AIM & Somewhat useful & $50-60$ & Not useful & $\begin{array}{l}\text { ANA solid phase assays superior to ANA IFF; J0-1 reactivity can be } \\
\text { missed by ANA HEp-2 }\end{array}$ \\
\hline MCTD & Very useful & $90-100$ & Not useful & High titer anti U1-RNP are highly indicative for MCTD \\
\hline JCA/JIA & Somewhat useful & $50-60$ & Very useful & Useful for subset that are at risk of developing uveitis \\
\hline $\begin{array}{l}\text { PBC } \\
\text { RA }\end{array}$ & Very useful & $50-80$ & Not proven & ANA IFF superior to solid phase assays \\
\hline APS & Not useful & $15-20$ & Not useful & Homogenous and speckled staining are the most common patterns \\
\hline $\begin{array}{l}\text { AT } \\
\text { Cancer and } \\
\text { paraneoplastic } \\
\text { syndromes }\end{array}$ & $\begin{array}{l}\text { Not useful } \\
\text { or utility not } \\
\text { established }\end{array}$ & $\begin{array}{l}\text { No-70 } \\
\text { Useful }\end{array}$ & Not useful & Might indicate systemic autoimmunity in primary APS patients \\
\hline
\end{tabular}

Abbreviations: AIH: autoimmune hepatitis; AIM: autoimmune inflammatory myopathy (polymyositis, dermatomyosisis); APS: anti-phospholipid syndrome; AT: autoimmune thyroiditis; JCA/JIA: juvenile chronic arthritis/juvenile inflammatory arthritis; MCTD: mixed connective tissue disease; PBC: primary biliary cirrhosis; RA: rheumatoid arthritis; SjS: Sjogren's syndrome; SLE: systemic lupus erythematosus; SSc: systemic sclerosis. NOTE: prevalence values are based on diagnostic samples (not treated patients)

Observations of the "LE cell" by Hargraves et al in 1948 led to the first laboratory test for ANA. This was an important discovery, as it provided the clinicians with a test that could be used to support the diagnosis of SLE. Previously, the diagnosis of SLE often could not be established until tissue specimens were obtained. Even though the lupus erythematosus (LE) cell preparation was recognized as a useful laboratory test, it soon became apparent that it was neither absolutely sensitive nor specific for the diagnosis of SLE. In an effort to further explain and refine this test, work conducted in a number of laboratories led to the recognition that the factors responsible for the LE cell phenomenon were a family of antibodies to various nuclear constituents. ${ }^{6}$ ANA detection by indirect immunofluorescence assay (IIFA) was first described in 1950 by Coons and Kaplan. ${ }^{7}$ An assortment of tissue types were used to detect ANA, and many of the early studies assessing clinical utility of the ANA test in SLE and other diseases used kidney or liver sections from rats or mice as substrates. Compared with the LE cell preparation, the immunofluorescent ANA test on rodent tissues was more sensitive for the diagnosis of SLE. However, this increased sensitivity was associated with reduced specificity, and substantial numbers of patients with other diseases and even healthy persons were found to have a positive ANA test result. ${ }^{8}$

Analysis of the results of ANA tests on animal tissue substrates revealed different appearances or patterns of immunofluorescent staining. It became standard practice for laboratories to report the patterns observed (eg. Speckled, homogenous/diffuse, rim/peripheral, nucleolar, or centromere) in addition to titers for positive ANA test results. Using laboratory techniques such as immunodiffusion, immunoprecipitation, radioimmunoassay (RIA), hemagglutination, and enzyme immunoassay (EIA), it has been shown that ANA-positive sera react with several different nuclear antigens. Reactivity with these antigens is more disease specific than the above-mentioned patterns and may also provide clinically useful prognostic information. ${ }^{3}$ Over the past decade, most laboratories worldwide have come to use a human tumor cell line substrate (the HEp-2 cell line) for routine ANA testing. ${ }^{8}$ The HEp-2 substrate has largely replaced rodent tissue and has become the standard substrate for performing the ANA test. Most relevant literature in recent years is based on results obtained with HEp-2 cells. This 'gold' standard technique is at present performed using HEp-2 cells or variants of this cell line (i.e. HEp-2000). ${ }^{9}$ There are several important differences between these 2 methods of ANA testing. The human cell line is more sensitive than the rodent line for the detection of ANAs. As a result, virtually all SLE patients have a positive ANA finding with use of the HEp-2 substrate. Increased sensitivity results from the expression of more relevant nuclear antigens in the human tumor cells. For example, rodents do not express Ro (SS-A) antigen. Also, centromeres, nucleoli, and other cellular organelles are more readily seen in transformed tumor cells like HEp-2. A sizable number of patients, from whom the term "ANAnegative lupus" was coined, have reactivity predominantly with Ro (SS-A). ${ }^{10}$ Others have nucelolar reactivity that is not readily detected on rodent tissue substrates. While such patients may have had negative ANA test results on rodent 
Table 2: Overview of defined ANA patterns (modified from Wiik et al., 2010)

\begin{tabular}{|c|c|}
\hline Pattern group & Pattern \\
\hline $\begin{array}{l}\text { Nuclear envelope } \\
\text { (membrane) }\end{array}$ & $\begin{array}{l}\text { Smooth nuclear envelope } \\
\text { Punctuate nuclear envelope }\end{array}$ \\
\hline Nuclear & $\begin{array}{l}\text { Homogeneous pattern } \\
\text { Large speckled } \\
\text { Coarse speckled } \\
\text { Fine speckled } \\
\text { Fine grainy Scl-70-like } \\
\text { Pleomorphic speckled (e.e. PCNA) } \\
\text { Centromere } \\
\text { Multiple nuclear dots } \\
\text { Coiled bodies } \\
\text { Dense fine speckled } \\
\text { Isolated metaphase chromosomes }\end{array}$ \\
\hline Nucleolar & $\begin{array}{l}\text { Homogeneous nucleolar } \\
\text { Clumpy nucleolar } \\
\text { Punctuate nucleolar }\end{array}$ \\
\hline $\begin{array}{l}\text { Mitotic spindle } \\
\text { apparatus }\end{array}$ & $\begin{array}{l}\text { Centriole } \\
\text { Spindle pole } \\
\text { Spindle fiber } \\
\text { Midbody } \\
\text { CENP-F }\end{array}$ \\
\hline Cytoplasmic & $\begin{array}{l}\text { Diffuse } \\
\text { Fine speckled } \\
\text { Mitochondrial } \\
\text { Discrete dots } \\
\text { Golgi complex } \\
\text { Intercellular contact proteins } \\
\text { Fibers and cytoskeleton } \\
\text { Rods and rings }\end{array}$ \\
\hline
\end{tabular}

tissue substrates, they are almost always positive when the HEp-2 substrate was used. ${ }^{11}$

\section{ANTI-NUCLEAR ANTIBODY}

ANA has two broad subtypes:

\section{Autoantibodies to DNA and histones}

These include antibodies against single and double stranded DNA (dsDNA) discovered way back in 1957. Significant levels of anti-dsDNA antibodies are considered to be confirmatory in diagnosis of SLE. This was followed by detection of anti-histone antibodies in 1971 which are indicative of durg-induced SLE.

\section{Autoantibodies to extractable nuclear antigens (ENA)}

Besides DNA and histones, autoantibodies also target other nuclear antigens. Theses nuclear antigens were named ENA as originally they were extracted from the nuclei with saline. ${ }^{12}$ Autoantibody to Smith antigen $(\mathrm{Sm})$ which is considered to be specific for SLE was the first antiENA detected in $1966 .{ }^{13}$ Although these ENA are disease specific, still a significant overlap exists. The sensitivity and specificity also varies depending upon the type of underlying CTD.${ }^{14}$ Clinical utility of ANA testing in different diseases can be seen in Table $1 . .^{15}$

\section{Screening and profile assay for ANA detection}

\subsection{ANA by Indirect Immunofluorescence on HEp-2 cells.}

For well over the last decade, the IIF HEp-2 assay was being replaced by newer technologies for the detection of ANA and several large laboratories switched to automated high throughput immunoassay platforms. ${ }^{16}$ However, in 2010, a position paper was published indicating that IIF on HEp-2 cells should remain the "gold standard" for the detection of ANA, triggering a renaissance of the IIF ANA test. ${ }^{17}$ However, standardization of this assay is difficult due to inter-manufacturer variations in the substrate and the fixation process, characteristics of the secondary antibody used. Detection of ANA by IIF may also yield false negative results even in the presence of high titers of antibodies, such as those directed to SS-A, Ro52, Jo-1 and others. Additionally, the challenge of significant variation of staining patters on the ANA HEp-2 IIF substrates obtained with slides from different manufactures has led to a proposed nomenclature for IIF pattern. ${ }^{18}$ (Table 2)

\subsubsection{Automated Pattern Recognition of the ANA HEp-2 Test.}

Computer assisted pattern recognition for ANA testing on HEp-2 cells has been described more than ten years ago. Automated hardware and software-based pattern recognition platforms that allow for the identification and archiving of IIF patterns obtained on HEp-2 cell substrates; however, they have only become available during the last few years. The operating principle of these new automated systems is acquiring, storing, and analyzing of digital images of stained IIF slides and displaying them on high resolution computer monitors. The inherent technical difficulties of processing and reading IIF slides (manual reading, real time interpretation, need for dark room, and handwritten results transcription) make traditional IIF methods difficult to fit in the workflow of modern, automated laboratories. The new automated systems are powerful workflow and operational tools that can eliminate the need for a darkroom and separate image acquisition from image interpretation and have the potential to improve the quality and utility of the ANA HEp-2 assay. ${ }^{19,20}$

The currently available automated ANA IIF image analyzing systems include NOVA View (INOVA Diagnostics, San Diego, US), Aklides (Medipan, Berlin, Germany), G-Sight (Menarini, Glorence, Italy), EuroPattern (Euroimmun, Lubeck, Germany), Image Navigator (ImmunoConcepts,Sacramento, US), and Helios (Aesku, Wendelsheim, Germany). ${ }^{21-23}$ The systems differ from each other with respect to the use of DNA-binding counterstains, such as DAPI, the cell substrate used, the throughput, the number of patterns that can be identified, and user friendly 


\begin{tabular}{|c|c|c|}
\hline \multicolumn{3}{|l|}{ Most commonly recognized patterns } \\
\hline Nuclear patterns & Related antigens & Related diagnosis \\
\hline $\begin{array}{l}\text { Homogenous } \\
\text { Coarse speckled } \\
\text { Fine speckled } \\
\text { Centromere } \\
\text { Nucleolar }\end{array}$ & $\begin{array}{l}\text { dsDNA, histones, chromatin, HMG } \\
\text { U1-SnRNP, U2-6 snRNP, nuclear matrix } \\
\text { SSA,SSB, Topo-1 } \\
\text { Kinetochore, CENP-A, B,C,F } \\
\text { PM/Scl }\end{array}$ & $\begin{array}{l}\text { SLE, drug induced SLE, JIA } \\
\text { MCTD,SLE, Raynaud,SSc,SS,UCTD } \\
\text { SLE,SS,SSc,IM,MCTD } \\
\text { SSc, Raynaud's } \\
\text { SSc, Raynaud's, IM, overlap }\end{array}$ \\
\hline Cytoplasmic patterns & Related antigens & Related diagnosis \\
\hline $\begin{array}{l}\text { Diffuse } \\
\text { Fine speckled }\end{array}$ & $\begin{array}{l}\text { RibP, Jo-1 } \\
\text { Jo-1, SRP, PDH }\end{array}$ & $\begin{array}{l}\text { SLE, IM } \\
\text { IM, DM,PBC, Interstitial lung disease }\end{array}$ \\
\hline \multicolumn{3}{|l|}{ Less commonly recognized patterns } \\
\hline Nuclear patterns & Related antigens & Related diagnosis \\
\hline $\begin{array}{l}\text { Peripheral/rim or nuclear envelope } \\
\text { Dense fine speckled } \\
\text { Pleomorphic cell cycle speckled } \\
\text { Necleolar } \\
\text { Multiple/ Few nuclear dots } \\
\text { Centrosome/centriole } \\
\text { Mitotic spindle }\end{array}$ & $\begin{array}{l}\text { Lamins, LAP } 1 / 2 \text {, nuclear envelope } \\
\text { DFS70/LEDGF-P75 } \\
\text { Auxillary protein proliferating cell nuclear } \\
\text { antigen } \\
\text { U3-SnRNP } \\
\text { Sp100, PML bodies, p80-coilin } \\
\text { Enolase, ninein,pericentrin } \\
\text { NuMA/centrophilin }\end{array}$ & $\begin{array}{l}\text { SLE, RA, PBC }<\text { IM autoimmune liver disease } \\
\text { Healthy subjects and inflammatory conditions } \\
\text { SLE, Lymphoporliferative disease, SS } \\
\text { SSc } \\
\text { PBC,CAH,SS } \\
\text { SSc, Raynaud's, inflammatory disease } \\
\text { RA, Inflammatory conditions, pneumonia }\end{array}$ \\
\hline Cytoplasmic patterns & Related antigens & Related diagnosis \\
\hline $\begin{array}{l}\text { Discrete speckled } \\
\text { Golgi complex } \\
\text { Cytoplasmic fibers }\end{array}$ & $\begin{array}{l}\text { Endosome, GW/Processing bodies } \\
\text { Golgi proteins } \\
\text { Actin, cytokeratin,tropomyocin,vimentin }\end{array}$ & $\begin{array}{l}\text { Neurological conditions, SS,SLE,RA,PBC } \\
\text { SLE,SS,RA,Cerebellar ataxia } \\
\text { CAH,DM,Infections, inflammatory conditions }\end{array}$ \\
\hline
\end{tabular}

Within the many patterns that can be distinguished the ones specified in the upper part of the table are the most commonly recognized. The relationship between pattern and antigen specificity may differ in certain conditions. Similarly, the specific antigens marked in bold are the most commonly detected by reflex testing, although other antigens may be of importance in different clinical conditions. Less common pattern are specified in the lower part of this table. CAH, chronic autoimmune hepatitis; CENP, centormere protein; DFS, dense fine speckled; DM, dermatomyositis; dsDNA, double-stranded DNA; HMG, high mobility group;IM, inflammatory myopathies; JIA,juvenile idiopathic arthritis; MCTD, mixed connective tissue disease; PBC, primary biliary cirrhosis; $P D H$, pyruvate dehydrogenase; $P m / S c l$, polymyositis/scleroderma; RA, rheumatoid arthritis; RNP, ribonucleoprotein; SLE, systemic lupus erythematosus; SRP,signal recognition particle; SS, Sjogren 'ssyndrome; SSc, Systemic sclerosis; Topo-1, topo-isomerase 1; UCTD, undifferentiated connective tissue disease.

features of the software.

Generally, these automated systems are based on a microscope fitted with an automated stage, a CCD digital camera, a LED light source, and software that controls the moving parts and directs image acquisition. All systems perform some kind of fluorescent light intensity measurement and use the results for preliminarily categorization of the samples as positive or negative and for pattern analysis. The automated reading is followed by human visual interpretation of the digital images that are displayed on a computer monitor, allowing user confirmation or revision of the automated results. By providing good quality digital images and other objective information, these automated systems support the operator's decision making and increase the consistency between readers and readings. In addition, the digital images can be stored and training, documentation, follow-ups, and second opinion purposes. In the future, these digital images might also become part of the patient's electronic medical record. At present, the system are highly reliable in their ability to discriminate positive from negative reactions and to estimate fluorescence intensity, but the accuracy and robustness of patter recognition does to reach the accuracy of human interpretation. An important feature is, the quality of the digital images, enabling the operators to make the same clinically relevant interpretation as they would make using a conventional microscope. Some systems offer automated assessment of ANA end-point titers on a single serum dilution, thereby eliminating the need for serial dilutions. Moreover, the potential integration of the automated digital IIF systems with laboratory information system provides sample traceability, and eliminates manual transcription and associated transmittal errors, thereby improving patient safety. The systems also hold the promise to reduce hands on time. Work flow studies using different systems are required to analyze the efficiency benefits of this systems. ${ }^{22}$

\subsection{ANA Screening ELISA}

There are two types of ELISA methods currently used in ANA testing. One is called generic assay which detects ANA of broad specificity similar to IF-ANA and other is antigen specific assay that detects ANA and reacts with a single autoantigen i.e. dsDNA, SS-A, SS-B, Scl-70, Sm etc. In antigen specific assay multiple antigens are coated on the microtitre plates, usually a combination of SSA, SSB, Sm and U1-RNP, with many also including Jo-1 and Scl70. 


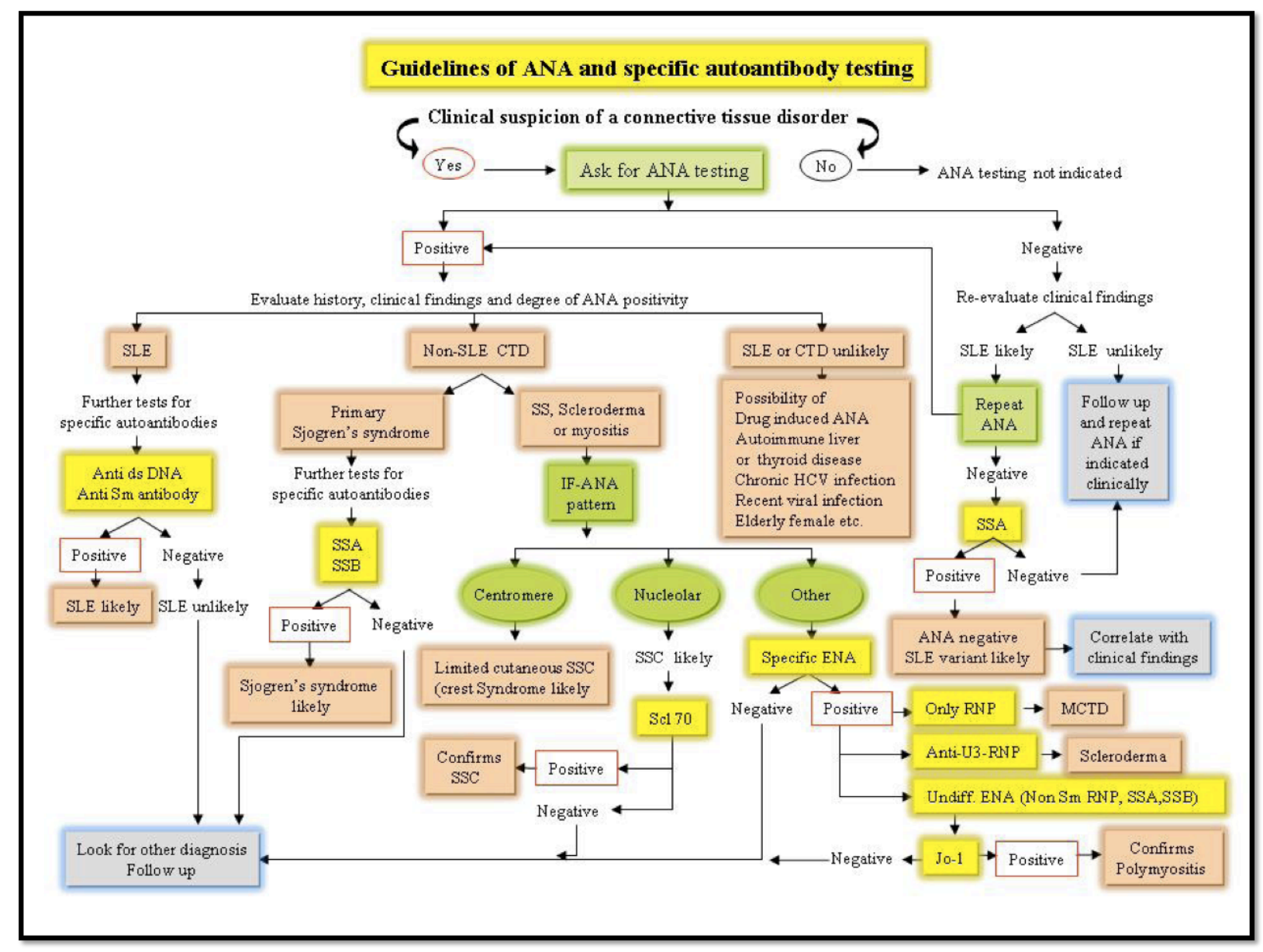

Figure 1:Algorithmic approach for ANA testing.

This new test is both highly specific and sensitive and substantially decreases the time involved with screening large number of patient samples. ELISA is therefore becoming the most widely used method not only for routine screening but also for detection of specific ANA. Although the second multicentre European study showed that ELISA methods are improving, the recent study by Bizzaro et al suggests that the problem of false positive results in ELISA is still widespread. ${ }^{24}$ The ELISA techniques have also been found to miss a low titer positive ANA as well as sera with specific ANA. It remains to be seen from further studies whether the performance of screening ANA tests by ELISA would match that by the fluorescent technique.

\subsection{Line Immunoassay}

A broad range of line immunoassays are available and they are typically used to confirm autoantibodies previously identified by HEp-2 ANA IIF or other screening immunoassays. Despite their ease of use, line immunoassays have some drawbacks including the lack of sensitivity and specificity for certain autoantibodies. ${ }^{25}$ However, line blot is comparable to ELISA in sensitivity and specificity and automated interpretation is also possible. ${ }^{26}$

\subsection{Dot Blot}

The dot blot method is a qualitative assay, which utilizes strips of nitrocellulose on which purified antigens are blotted at pre-located spots. The antigen sources used are bovine and rabbit thymus (for SSA, Sm and Scl-70) or calf spleen and rabbit thymus (for $\mathrm{SSb}$ and $\mathrm{Sm} / \mathrm{RNP}$ ). The strips are incubated with a 50-fold dilution of patient serum followed by incubation with an alkaline phosphatase protein A conjugate. Finally the test strips are stained with 5 bromo-4-chloro-3-indolylphosphate/nitroblue tetrazolium. Positive strip are stained as a blue spot. The dot blot test is advantageous for time management as the test requires just 30 minutes, can be easily performed and relatively cheaper. A major drawback however is the blotting of RNP antigen in combination with $\mathrm{Sm}$ antigen. This implies that if both the Sm spot and the Sm/RNP spot are positive the presence of $\mathrm{Sm}$ antibodies alone cannot be distinguished from the combined presence of Sm and RNP antibodies. ${ }^{27}$

\subsection{Multiplex Bead Based Assays}


The newly developed multiplex immunoassay (MIA) enables the detection of multiple specific ANA as separate entities at the same time. Multiplex assays based on the Luminex technology use addressable laser beads and are therefore often referred to as ALBIA (addressable laser bead immunoassays).$^{28}$ In MIA the patient sera is incubated in a well containing a multiplexed mixture of the bead suspension. The bead suspension consists of polystyrene microspheres that are conjugated with different antigens and nuclear extract of HEp-2 cells. If the patient serum contains antibodies to any of the antigens or HEp-2 nuclear extract, the antibody will bind to the immobilized antigen on 1 or more of the bead sets. The antibody-antigen-bead complex is then incubated with phycoerythrin conjugated goat antihuman IgG and the bead suspension is then analyzed by the immunoassay analyzer. The beads are uniquely identified by their corresponding fluorescent dye, and the amount of phycoerythrin conjugate is determined for each antigen. Multiplex ANA testing is being claimed to be more efficient and technically less challenging than IF ANA screening, decrease false positivity, removes subjectivity and is more efficient than conventional ELISA. ${ }^{29}$

\subsection{Flowcytometry}

Flowcytometry with autoantigen-coated fluorescent beads has been gaining popularity in recent years. Fluorescent beads-based techniques, also commonly referred to as Reflex ANA, are claimed to have multiple advantages such as simultaneous testing for recognition of several antigens, automation, cost effectiveness and high sensitivity. However, most significant limitation of this method is that it provides only a single result for each analysis.

\subsection{Antigen microarray}

Antigen microarray currently not widely performed but may be an excellent advancement for simultaneous measurement of multiple ANA. This is a nanotechnology technique in which pre-synthesized antigens are printed on polystyrene and incubated with serum samples and then with horseradish peroxidase-conjugated secondary antibodies and chemiluminescent substrates. Light signals produced are captures by a charge-coupled device camera based chip reader. Antibodies are quantified by use of calibration curves. The results are largely comparable to those obtained with techniques currently used in clinical laboratories. ${ }^{30}$

\section{Patterns and Clinical utility of ANA}

The IIF assay nuclear and cytoplasmic patterns detected on HEp-2 substrates are presented in Table 3.

\section{Should ANA test be repeated or should other tests be done if the result is Negative?}

Other than in exceptional cases in which an error in testing is strongly suspected, immediately repeating a negative
ANA test is not necessary. However, because the clinical progression of systemic rheumatic disease is often dynamic and evolves over time, it may be worthwhile to report the NAN test at a future time, particularly if the clinical course changes. Using HEp-2 cells as a substrate has virtually eliminated false-negative ANA results.

\section{What other testing should be done following a positive ANA test result?}

ANA is a generic testing for autoantibodies. If ANA is positive further testing can be done by either reflex or cascade testing, where in a panel of tests are done by Immunoblot or Line immunoassay. Another method is to perform specific autoantibodies to which a clinical suspicion is present. Tests for specific autoantibodies are virtually never positive in patients who do not have a positive ANA test. Also, with the exception of antibodies to dsDNA, variation in the concentrations or titers of these antibodies has not been shown to provide useful clinical information. Therefore, repeating tests (other than the anti-dsDNA), if the results are positive, is not indicated. Because the diseases associated with these tests tend to be dynamic over time, negative findings might be rechecked if the clinical circumstances change considerably.

\section{If the clinician suspects SLE, what tests may help confirm the diagnosis?}

The initial test to be obtained the generic ANA test. In some case, for example, when the clinical picture is characteristic of SLE, tests other than the ANA to establish the diagnosis may not be needed. However, as noted above, the ANA test result may be positive in a number of other diseases, some of which have clinical features similar to SLE. In such cases, 2 additional tests can help establish the diagnosis of SLE: tests for autoantibodies to dsDNA (anti-dsDNA) and autoantibodies to the Smith antigen (anti-Sm). High titers of anti-dsDNA antibodies are more specific for SLE than are results just above the normal range. Weakly positive antidsDNA results may occur in patients who do not have SLE. This is particularly true for anti-dsDNA analysis performed by the ELISA method. The percentage of SLE patients who have anti-dsDNA antibodies varies in published series from $25 \%$ up to $85 \%$. In summary, in the appropriate clinical setting, the finding of anti-dsDNA antibodies supports the diagnosis of SLE, while the absence of anti-dsDNA antibodies does not rule out SLE. ${ }^{31}$

\section{After the diagnosis of SLE is made, what tests provide} information about prognosis?

Physicians would like to know about the prognosis of the disease once patient is diagnosed with SLE. Presence of anti-dsDNA autoantibody is not as strong as it is for diagnosis. Therefore, the finding of anti-dsDNA antibodies by itself does not establish whether the patient has active SLE or active lupus nephritis. The anti-dsDNA must always 
be interpreted in the context of the complete clinical picture. For example, in SLE patients with some indication that they may have renal involvement (eg. Proteinuria), the demonstration of a positive anti-dsDNA test result would make lupus nephritis more likely and should prompt the treating physician to investigate renal function further and perhaps to initiate treatment. On the other hand, if an asymptomatic SLE patient is found to have anti-dsDNA, this does not necessarily indicate active disease or a need for therapy. Watchful waiting may be the best option in such a case.

\section{Guidelines of ANA and specific autoantibody testing}

The following recommendations are organized to simulate the thought processes a clinician might go through when ordering and interpreting an ANA test for disease diagnosis. No tests for autoantibodies should be performed without a clinical evaluation that leads to a presumptive diagnosis. An algorithmic approach for ANA testing would be helpful for both the treating physician and the pathologist. ${ }^{4}$ (Fig. 1) A titer of $1: 160$ is taken as significant for the diagnosis of connective tissue diseases in majority of laboratories..$^{32,33}$

\section{Drawbacks of ANA testing}

Although an American College of Rheumatology expert panel has recognized indirect fluorescent assay as the gold standard for ANA testing, the method has a number of acknowledge shortcomings, including interobserver variability and differences in sensitivity and specificity of the test depending on the substrate used (eg. Different HEp2 kits). Although a positive ANA test result can reflect an interaction between serum antibodies and as many as 150 different nuclear antigens, only a minority of these antigens are well described and have established associations with disease, where as many of the remaining antigen-antibody reactions may not be clinically relevant. Other widely used, commercially available ANA kits use different techniques, including ELISA and multiplex bead assay, and studies have demonstrated that ANA test results depend partly on the assay used. ${ }^{34}$

Multiple studies show ANA positivity to be highly prevalent in both the general and various patient populations. In a study conducted in Belgium, $42.6 \%$ of 6422 consecutively tested patients at a large community hospital were ANApositive $(\geq 1: 80)$, and another study showed prevalence of ANA positivity $(\geq 1: 40)$ in a group of 304 healthy individuals to be $54.3 \%$. Even children have been found to have a high background ANA positivity rate. Of 1369 consecutive samples assessed at one academic hospital, $36 \%$ were ANA positive with a titre of $\geq 1: 40$ (only $8.2 \%$ of whom were determined to have systemic lupus erythematosus or an overlap syndrome). Of note, even when the cutoff for ANA positivity is defined more rigorously (as a dilution $\geq 1: 160$ ), the rate of ANA positivity in the general population remains fairly high, at approximately $9.5 \%{ }^{35,36}$

\section{Future perspectives}

A lot of advancements have come in the field using indirect immunofluorescence for diagnosis of connective tissue diseases; however, in terms of automation and standardization, it has not been able to keep pace with most other analytical techniques used in diagnostic laboratories. Although there are already some automation solutions for IIF incubation in the market, the automation of result evaluation is still in its infancy. Several limitations still persist. First, the terminology and nomenclature used to identify and refer to various autoantibodies need to be standardized. Second, the classification criteria and nomenclature of individual SARD and related autoimmune disease must continue to evolve and keep abreast of biomarker identification. Third, the corresponding immunoassays and diagnostic platforms used for the various clinical applications need to be based on standardized reference samples of defined specificities. This possibility could include the development and validation of disease specific screening assays on solid phase technologies. Fourth, diagnostic algorithms need to be adjusted to the clinical and laboratory setting considering the referral pattern, the sample testing volume, and health economic aspects. ${ }^{15}$

\section{REFERENCES}

1. Solomon DH, Kavanaugh AJ, Schur PH. Evidence-based guidelines for the use of immunologic tests: antinuclear antibody testing. Arthritis Rheum 2002;47:434-44. Crossref

2. Agmon-Levin N, Shapira Y, Selmi C, et al. A comprehensive evaluation of serum autoantibodies in primary biliary cirrhosis. $\mathrm{J}$ Autoimmun 2010;34:55-8.Crossref

3. Walravens M. Systemic disease and the detection of nuclear and anticytoplasmic antibodies. A historical review. Clin Rheumatol 1987;69-17.

4. Kumar Y, Bhatia A, Minz RW. Antinuclear antibodies and their detection methods in diagnosis of connective tissue disease: a journey revisited. Diagnostic Pathology 2009;4:1. doi:10.1186/17461596-4-1. Crossref

5. Klemperer P, Pollack AD, Baehr G. Pathology of disseminated lupus erythematosus. Arch Pathol. 1941;32:569-631.

6. Von Muhlen CA, Tan EM. Autoantibodies in the diagnosis of systemic rheumatic disease. Semin Arthritis Rheum. 1995;24;23-58. Crossref

7. Coon AH, Kaplan MH. Localization of antigen in tissue cells; improvements in a method for the detection of antigen by means of fluorescent antibody. J Exp Med. 1950;91:1-13. Crossref

8. Forslid J, Heigl Z, Jonsson J, Secheynius A. The prevelance of antinuclear antibodies in substrate. Clin Exp Rheumatol. 1994; 12:137-41.

9. Meroni PL, Schur PH. ANA screening: an old test with new recommendations. Ann Rheum Dis. 2010;69:1420-2. Crossref

10. Dore N, Synkowski D, Provost TT. Antinuclear antibody determinations in Ro (SS-A) positive, antinuclear antibody negative lupus and Sjogren's syndrome patients. J Am Acad Dermatol. 1983;8:611-5. Crossref

11. Manoussakis M, Garalea K, Tzioufas A, Moutsopoulos H. Testing for antibodies to ENA and to dsDNA is not indicated in FANA-negative sera. Clin Rheumatol. 1988;7:465-96.

12. Fishbein E, Alarcon-Segovia D, Vega JM. Antibodies to histones in 
systemic lupus erythematosus. Clin Exp Immunol. 1979;46:145.

13. Tan EM, Kunke HG. Characteristics of a soluble nuclear antigen precipitating with sera of patients with systemic lupus erythematosus. J Immunol. 1966;96:464.

14. Colglazier CL, Sutej PG. Laboratory testing in rheumatic disease: a practical review. South Med J. 2005;98:185-91. Crossref

15. Mahler M, Meroni PL, Bossuyt X, Fritzler MJ. Current concepts and future directions for the assessment of autoantibodies to cellular antigens referred to as anti-nuclear antibodies. Journal of Immunology Research. 2014; Article ID 315179, 18 pages. Crossref

16. Nossent H, Rekvig OP. "Antinuclear antibody screening in this new millennium: farewell to microscope?" Scandinavian Journal of Rheumatology. 2001;30:123-6. Crossref

17. Meroni PL, Schur PH. " ANA screening: an old test with new recommendations," Annals of the Rheumatic Disease. 2010;69:142022. Crossref

18. Wiik AS, Madsen H, Forslid J, Charles P, Meyrowitsch J. Antinuclear antibodies: a contemporary nomenclature using HEp-2 cells. Journal of Autoimmunity. 2010;35:276-90. Crossref

19. Perner P, Perner H, Muller B. Mining knowledge for HEp-2 cell image classification, artificial intelligence in medicine. 2002;9:17-22.

20. Voigt J, Krause C, Rohwader $\mathrm{F}$ et al. Automated indirect immunofluorescence evaluation of antinuclear autoantiboides on HEp-2 cells. Clinical and developmental immunology. 2012; Article ID 651058,7 pages.

21. Schouwers S, Bonnet $\mathrm{M}$, Verschueren et al. Value added reporting of antinuclear antibody testing by automated indirect immunofluorescence analysis. Clinical chemistry and laboratory medicine. 2014;52:547-51. Crossref

22. Roggenbuck D, Hiemann R, Schierack P, Reinhold D, Conrad K. Digital immunofluorescence enables automated detection of antinuclear antibody endpoint titers avoiding serial dilution. Clinical chemistry and laboratory medicine. 2013:1-3.

23. Bossuyt X, Cooreman S, De BH et al. Detection of antinuclear antibodies by automated indirect immunofluorescence analysis. Clinica chimica Acta. 2013;415:101-6. Crossref

24. Bizzaro N, Tozzoli R, Tonutti E et al. variability between methods to determine ANA, anti-dsDNA and anti-ENA auto antibodies: a collaborative study with the biomedical industry. J Immunol Methods. 1998;219:99-107. Crossref

25. Bordet C. Performance of the Inno-lia ANA test in the detection of the main autoantibodies involved in connective tissue disease. Annales de Biologie Clinique. 2001;59:767-68.
26. Damoiseaux J, Boesten K, Giesen J, Austen J, Tervaert JWC. Evaluation of a Novel line blot immunoassay for the detection of antibodies to extractable nuclear antigens. Ann NYA Sci. 2006;1050:340-7. Crossref

27. Ermens AAM. Simple dot blot method evaluated for detection of antibodies against extractable nuclear antigens. Clin Chem. 1997;43:2420-22.

28. Fritzler MJ, Fritzler ML. The emergence of multiplexed technologies as diagnostic platforms in systemic autoimmune disease. Current Medicinal Chemistry. 2006;13:2503-12. Crossref

29. Copple SS, Martins TB, Masterson C, Joly E, Hill HR. Compariosn of three multiplex immunoassays for detection of autoantibodies to extractable nuclear antibodies using clinically defined sera. Ann N Y Acad Sci. 2007;1109:464-72. Crossref

30. Feng Y, Ke X, R Ma, Chen Y, Hu G, Liu F. Parallel detection of autoantibodies with microarrays in rheumatoid disease. Clin chem. 2004;50:416-22. Crossref

31. Kavanaugh A, Tomar R, Reveille J, Solomon DH, Homburger HA. Guidelines for clinical use of the antinuclear antibody test and tests for specific autoantibodies to nuclear antigens. Arch Pathol Lab Med. $2000 ; 124 ; 71-81$.

32. Ghos P, Dwivedi S, Naik S et al. Antinuclear antibodies by indirect immunofluorescence: optimum screening dilution for diagnosis of systemic lupus erythematosus. Indian J Med Res. 2007;126:723-7.

33. Kiuttu J, Kartikainen A, Makitalo R. Occurance of antinuclear antibodies in an unselected pregnancy population. Gynecol Obstet Invest. 1994;37:160-3. Crossref

34. Abeles AM, Abeles M. The clinical utility of a positive antinuclear antibody test result. The American Journal of Medicine. 2013;126:342-8. Crossref

35. Malleson PN, Sailer M, Mackinnon MJ. Usefulness of antinuclear antibody testing to screen for rheumatic diseases. Arch Dis Child. 1997;77:299-304. Crossref

36. Hayashi N, Koshiba M, Nishimura K, et al. Prevalence of disease specific antinuclear antibodies in general population: estimates from annual physical examinations of residents of a small town over a 5 year period. Mod Rheumatol. 2008;18:153-160. Crossref 